Original Article

\title{
Outcome of Experienced Based Learning (Field Trip) As a Learning Technique in Gaining Knowledge among Graduate and Post Graduate Nursing Students.
}

\author{
Malarvizhi G. ${ }^{1}$, H. Glory ${ }^{2}$, S. Rajeswari ${ }^{3}$, Bindu CVasanthi ${ }^{4}$ \\ ${ }^{1}$ Professor and HOD, Pediatric Nursing Department Cum Principal i/c, ${ }^{2}$ Associate Professor, ${ }^{3,4}$ Asst. Professor Department \\ of Pediatric Nursing, PSG College of Nursing, Coimbatore.
}

*Corresponding Author: M alarvizhi G., PSG College of Nursing, Avinashi Road, Peelamedu, Coimbatore - 641004.

Mobile: +91 94435 50665, E-mail : malarvizhi2k5@yahoo.co.in.

Received

: 01.03.2017

Review Completed : 19.05.2017

Accepted

:21.05.2017

Keywords : Experience based learning, Field Trip, Child welfare Agencies.

\begin{tabular}{|c|}
\hline Access this article online \\
\hline Quick Response Code \\
\hline
\end{tabular}

\begin{abstract}
Education brings changes in behavior of the individual in a desirable manner. It aims at all round development of an individual to become mature, self-sufficient, intellectually, culturally refined, socially efficient and spiritually advanced. In experience- based is that the experience of the learner occupies central place in all considerations of teaching and learning. A key element of experience-based learning is that learners analyze their experience by reflecting, evaluating and reconstructing it in order to draw meaning from it in the light of prior experience. The main aim of the study is to assess the knowledge of nursing students before and after Experience based learning and to determine the attitude of EBL at the end of the field trips. A quasi Experimental research design was adopted. Sample free technique was used to select the 90 B.sc and M.Sc (N) students. The data was collected by using semi structured knowledge questionnaire. Inferential and descriptive statistics was used to analyze the data. There was a significant difference in pre test and post test mean score ( $t=15.98$ at $p \varangle 0.001)$. A weak positive correlation was found between post- test knowledge and attitude. There is a significant improvement in knowledge of students in various child welfare services among the present students $(\bar{\chi}=3.18 \pm 421)$ than the previous year $(\bar{\chi}=2.86 \pm 371)$.
\end{abstract}

\section{Introduction}

Nursing education has expanded considerably postindependence. University education in nursing has brought about significant changes in nursing education. The type of nurses required today is an "all round personality". Education brings changes in behavior of the individual in a desirable manner. It aims at all round development of an individual to become mature, self-sufficient, intellectually, culturally refined, socially efficient and spiritually advanced $^{1}$.

Experiential learning emphasis on direct sense experience and in-context action as the primary source of learning. It is a naturalistic ongoing process of direct learning from life experiences. The salient feature of experience - based learning is that the experience of the learner occupies central place in all considerations of teaching and learning. This experience may comprise earlier events in the life of the learner, current life events, or those arising from the learner's participation in activities implemented by teachers and facilitators ${ }^{2}$.

A key element of experience-based learning is that learners analyze their experience by reflecting, evaluating and reconstructing it in order to draw meaning from it in the light of prior experience. In the present scenario Experienced Based Learning supports a more participative, learner-centered approach, which places an emphasis on direct engagement, rich learning events and the construction of meaning by learners. It is most useful in higher education learning and it encompasses incidental and lifelong learning ${ }^{3}$.

Specifically, fieldwork can have a positive impact on longterm memory due to the memorable nature of the fieldwork setting. Effective fieldwork and residential 
experience in particular, can lead to individual growth and improvements in social skills. M ore importantly, there can be reinforcement between the affective and the cognitive, with each influencing the other and providing a bridge to higher order learning. ${ }^{4}$

Experiential learning, or active learning, interactive learning, or "learning by doing" has resulted in positive outcomes. M ost experts agree that when students take an active role in the learning process the student's learning is optimized $^{3}$. We would like to measure their knowledge gained out of this learning experience and to know their opinion and feed back of field trip.

\section{Objectives of the Study}

1. To assess their knowledge of students on various child welfare services before and after Field trip.

2. To find the outcome of experienced based learning by comparing the knowledge gained out of Field visit in the evaluation method of multiple choice questions with assignment method of evaluation in the previous year.

3. To get their feedback and opinion related to child welfare services at the end of entire field trips.

\section{Materials and Methodology}

Quasi experimental one group pre -test and post-test design was used to assess the nursing students (90 - B.Sc Nursing III year students - 85, M.Sc Nursing I \& II year students-5) knowledge gained out of Field visit in the various child welfare services on Families for children, Podanur, Thayagam, ICDS, International Human Resource Development Centre for the Disabled Children, Meher's Village \& Shanthi Ashram. The study was conducted in PSG College of Nursing, Coimbatore during their scheduled observation visit. Sample free technique was used to select the samples. Previously the student's knowledge and performance were assessed only by the Assignments after the Field visit. In this study, the student's knowledge on various child welfare services were assessed by semi structured knowledge questionnaire before and after Field visit. The knowledge gained out of field visits were assessed by mean M CQ scoresfor the present students and compared with the mean assignment score previous year students. Student's feedback and refection on visit was obtained at the end of the field visit week.

\section{Statistical methods}

Descriptive and inferential statistics were used to analyze the data. Paired t-test was used to find out the difference between pre test and post test knowledge gained through experience based learning. The correlation was found between pre test and post knowledge by using Karl Pearson coefficient correlation.

\section{Results}

\section{Participant}

The final sample ( $\mathrm{N}=90$ students) consisted of predominantly females $90 \%$ and males were only ( $10 \%)$ with a mean age of $19.5 \mathrm{yrs}(\mathrm{SD}=1.6)$. Table 1 summarizes the Demographic data for the overall sample.

Table 1 : Participant Demographics on Child Welfare services through EBL

$(n=90)$

\begin{tabular}{|l|l|l|l|}
\hline \multicolumn{2}{|l|}{ Characteristic } & M ean \pm SD & Frequency \& percentage \\
\hline \multicolumn{2}{|c|}{ Age } & $19.5 \pm 1.6$ & \\
\hline Gender & Male & $19.3 \pm 0.5$ & $9(10 \%)$ \\
\hline & female & $19.6 \pm 1.7$ & $81(90 \%)$ \\
\hline
\end{tabular}

The Nursing students gained knowledge through experienced based learning. There was a significant improvement in the post test knowledge scores. (FFC, Thayagam 2.45, $\pm 2.80,4.42 \pm 1.50$, ICDS $=3.04 \pm 2.63,7.77 \pm 1.87$ ).

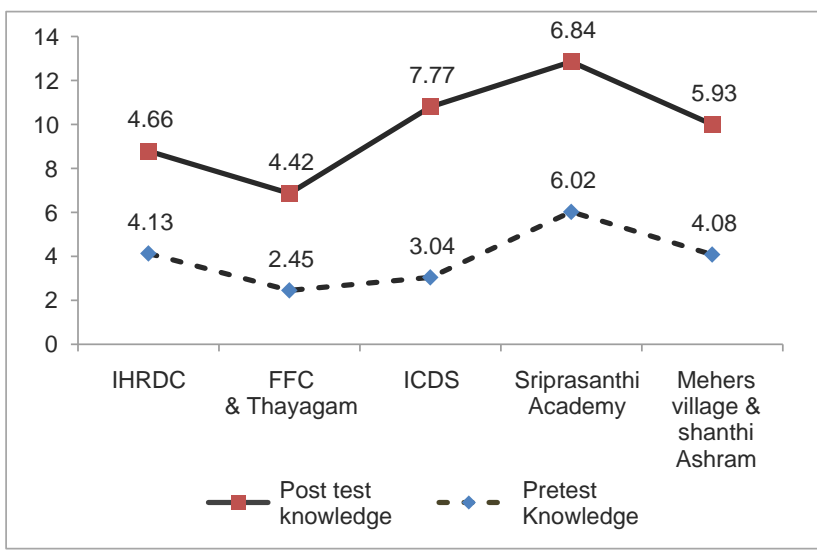

Figure 1 : Pre and post test knowledge of nursing students on Child welfare services gained by EBL 
Table.2 Comparison between Pre-test and Post- test Knowledge of nursing students on Child Welfare servicesthrough EBL

\begin{tabular}{|l|c|c|c|c|c|}
\hline $\begin{array}{l}\text { Knowledge of students } \\
\text { Gained through EBL }\end{array}$ & Mean & $\begin{array}{c}\text { Standard } \\
\text { deviation }\end{array}$ & t- Value & Table value & P-Value \\
\hline Pretest Knowledge & 4.31 & 1.06 & $15.98 * *$ & 1.98 & 0.001 \\
\hline Posttest Knowledge & 6.1 & 0.89 & & & \\
\hline
\end{tabular}

Note : Statistically significant $* * p \triangleleft 0.001$

Table. 2 shows that there was a significant difference between pretest and post- test mean knowledge scores. $(t=15.98$ at $p \varangle 0.001)$.

Table 3: Comparison of student's knowledge on Assignment method and M CQ M ethod in various child welfare services.

\begin{tabular}{|l|l|c|c|c|}
\hline S. No & Knowledge on child welfare services & $\bar{\chi}_{1}$ SD & Standard variance S & 95\%Confidence interval range Level \\
\hline 1. & Knowledge of students on assignment $(n=86)$. & $2.86 \pm 371$ & 0.137 & $2.14-3.59$ \\
\hline 2. & Knowledge of students on MCQ $(n=90)$. & $3.18 \pm 421$ & 0.177 & $2.36-4.01$ \\
\hline
\end{tabular}

Table. 3 shows that there is a significant improvement in knowledge of students in various child welfare services among the present students than the previous year, By virtue of this, M CQ method of pre assessment was created the curiosity among the students to learn in reality situation $(\bar{\chi}=3.18 \pm 421)$, Whereas in the previous year students the knowledge gained was assessed through assignments at the end of the visit $(\bar{\chi}=2.86 \pm 371)$.

The student's knowledge and attitude significantly improved after the Experienced Based Learning (Field Trip). Majority of the students $90 \%$ gave their feedback that the fieldtrip was a real experience and opportunity to learn in a real-world setting and appreciate the child welfare services rendered at various settings.

\section{Discussion}

Field trip was introduced in 1827 by George Shillibeer for a Quaker school at Abney Park in Stoke Newington, London, United Kingdom. Field trip Facilitates the learning of abstract concepts, motivate students through increased interest and curiosity and increases student-student and student-teacher social interaction.

The present study implies that there is a difference between pretest and post-test knowledge means scores. Significant improvement in knowledge was found among the students after exposure to EBL ( $t=15.98$ at $p \varangle 0.001$ ), M CQ method of pre assessment was created the curiosity among the students to learn in reality situation $(\bar{\chi}=3.18 \pm 421)$, Whereas in the previous year students the knowledge gained was assessed through assignments at the end of the visit ( $\bar{\chi}=2.86 \pm 371)$.

A similar pilot study was done to assess an experiential field trip as a novel method of enhancing medical knowledge in ambulatory pediatric feeding and safety among Sixtyseven medical students and resident physicians indicated that overall participants short-term knowledge significantly increased from $9.9 \pm 2.6$ to $15.4 \pm 2.2$ questions correct $(P=001)$, with statistically significant gains $(P<.001)$ on both the feeding and safety sections of the test. $^{5}$

An experimental study was conducted to examine the third year nursing student's opinions towards the integration of student-centered approach for field trip in M ental Health and Psychiatric Nursing Practicum at Thailand. The results suggested that student-centered approach should be implemented in advance in nursing education as a lifelong learning ${ }^{6}$.

The Correlation was assessed between the Post-test Knowledge and Attitude of nursing students on Child welfare services gained through EBL there is a weak positive correlation $(0.01, p=0.462)$ between post-test knowledge (6.1+_ 0.89) and attitude (44.86+3.35). However the student's knowledge. The student's knowledge and attitude significantly improved after the EBL(field trip).

A case study report among 12 learners, as part of their Diploma in Society Health and Development in Ashington, 
UK, demonstrated an increased depth of understanding on the day of the field trip however they were unable to transfer this to their assessment at a later date. ${ }^{7}$

\section{Conclusion}

Field trip provides real-world experience, increases the quality of education, and improves the social relations, outside of the four walls of a classroom. The idea behind this experiential learning is to contextualize knowledge in order to develop a deeper understanding. Many field trips combine educational content with team-building activities, such as working together to complete

\section{References}

1. TNAI (2002).Indian Nursing Year Book: New Delhi.

2. David A Kolb. Experiential Learning- Experience as the source of learning and development. $2^{\text {nd }}$ edition.

3. Mary McCarthy. Experiential Learning Theory: From Theory to Practice.2016;J BER(14)3,91-97

4. Rickinson,M. A review of Research on Outdoor Learning. Retrieved from:http:// www.teachernet.gov.uk/teachingandlearning/resource materials/growingschools/ (2004).1-72

5. Allen R., Hayley C., Paul D A. Field Trips as a Novel Means of Experiential Learning in Ambulatory Pediatrics. 2012; J Grad Med Educ. 4(2)

6. 246-249. doi: 10.4300/JGME-D-11-00173.1 .Poonruksa S,The Integration of Student-Centered Approach for Field Trip in Mental Health and Psychiatric Nursing Practicum: Case Studies among Third Year Nursing Students of Assumption University of Thailand. AUJT, 1.2007;0(4),225-231.

7. Paula Greenhalgh, A case Study on the Effectiveness of Field Trips as Part of Educational Programs:, 2011. Health Access and Social Care, Northumberland College2011. assignments and projects. In fact, it is often a good idea to go on a field trip to help create a bond between the students.

Good field trips can provide an integral part of the learning experience if they are planned well. The aim of this project is to consider how effective field trips are in providing contextualized knowledge and if this knowledge can then be easily transferred to workin the classroom.

\section{Limitations}

- The long-term retention of knowledge could not be assessed. 